NON-INVASIVE VASCULAR VERY-HIGH RESOLUTION

ULTRASOUND TO QUANTIFY ARTERY INTIMA LAYER

THICKNESS : VALIDATION OF THE FOUR-LINE PATTERN

Sundholm, Johnny K. M.

2019-08

Sundholm , J K M , Paetau , A , Albäck , A , Pettersson , T \& Sarkola , T 2019 , ' NON-INVASIVE VASCULAR VERY-HIGH RESOLUTION ULTRASOUND TO QUANTIFY ARTERY INTIMA LAYER THICKNESS : VALIDATION OF THE FOUR-LINE PATTERN ' , Ultrasound in Medicine \& Biology , vol. 45 , no. 8 , pp. 2010-2018 . https://doi.org/10.1016/j.ultrasmedbio.2019.04.01

http://hdl.handle.net/10138/316310

https://doi.org/10.1016/j.ultrasmedbio.2019.04.017

cc_by_nc_nd

acceptedVersion

Downloaded from Helda, University of Helsinki institutional repository.

This is an electronic reprint of the original article.

This reprint may differ from the original in pagination and typographic detail.

Please cite the original version. 
Sundholm Assessing Vascular Intima with Ultrasound

\section{Non-invasive vascular very-high resolution ultrasound to quantify artery intima layer thickness: validation of the four-line pattern}

Johnny K.M. Sundholm, MD ${ }^{1}$

Anders Paetau, MD, $\mathrm{PhD}^{2}$

Anders Albäck, MD, $\mathrm{PhD}^{3}$

Tom Pettersson, MD, $\mathrm{PhD}^{4}$

Taisto Sarkola, MD, $\mathrm{PhD}^{1}$

${ }^{1}$ Children's Hospital, University of Helsinki and Helsinki University Hospital, Helsinki, Finland

${ }^{2}$ HUSLAB Meipa1 pathology laboratory \& Haartman Institute, University of Helsinki, Helsinki, Finland

${ }^{3}$ Department of Vascular Surgery, University of Helsinki and Helsinki University Hospital, Helsinki, Finland

${ }^{4}$ Department of General Internal Medicine and Geriatrics, University of Helsinki and Helsinki University Hospital, Helsinki, Finland

Abstract word count 169, Figures 3, Tables 2, References 32, Supplemental tables 6 , Supplemental figures 4 .

Address for Correspondence: Johnny Sundholm, MD, Children's Hospital, Helsinki University Hospital, Stenbäckinkatu 11, POB 281, FIN-00029, Helsinki, Finland, Phone: +358504011154, Fax:+358947174706, e-mail: johnny.sundholm@helsinki.fi 


\section{Abstract}

Preliminary findings suggest that very-high resolution ultrasound (VHRU, $55 \mathrm{MHz}$ ) could differentiate arterial intima layer thickness (IT) non-invasively in vivo. We aimed to validate ultrasound derived IT measurements and describe a four-line pattern consistent with intimal thickening. VHRU was applied to temporal arteries of 37 patients with suspected giant cell arteritis without inflammation on histology. Anatomically matched ultrasound derived measurements of arterial layer thickness with the leading-edge method was compared to histology. Intimal thickening (IT>0.06 mm on histology) was identified as a fourline pattern in VHRU with a sensitivity of $96.3 \%$ and a specificity of $100 \%$. Histological and VHRU IT measurement agreement was excellent (mean difference $0.007 \mathrm{~mm}$; 95\%LOA 0.043-0.057) and ICC $0.923(95 \% \mathrm{CI} 0.833-0.964)$. Intra- and inter-observer agreements for VHRU IT was high: ICC $0.946(95 \% \mathrm{Cl} 0.877-0.976)$ and $0.872(95 \% \mathrm{Cl} 0.773-0.943)$. VHRU utilizing the leading-to-leading edge method allows accurate and reliable measurements of arterial IT in patients with IT $>0.06 \mathrm{~mm}$. Measurements of IT will provide the opportunity to explore early subclinical structural intimal changes in the arterial wall increasing with age.

Keywords: Vascular imaging, intima thickness, intima-media thickness, ultrasound biomicroscopy, methodology, very-high resolution ultrasound 


\section{Introduction}

2

3 increased cardiovascular mortality.(Enos et al. 1953; McNamara et al. 1971; Mönckeberg

4 1915; O'Leary et al. 1999) In 1984 Pignoli et al were among the first to introduce non-

5 invasive measurements of vascular wall-thickness using B-mode high-resolution ultrasound

6 (HRU).(Pignoli et al. 1984, 1986) In their landmark paper they compared ultrasound images

7 of the carotid artery with histology and described the double line pattern of the arterial far

8 wall. Since then, carotid intima-media thickness (IMT) has been shown to be an independent

9 predictor of cardiovascular risk and used as a surrogate marker for cardiovascular

10 disease.(Burke et al. 1995; Lorenz et al. 2018; Stein et al. 2008) In the aging population, an

11 increased IMT has been attributed mainly to intimal thickening with differences between

12 arteries and even between locations in the same artery.(Chowdhury et al. 2004; Nakashima

13 et al. 2002; Wilens 1951)

14 Due to the physical properties of ultrasound the echogenic region is created at the interface of two different mediums with the leading edge defining the true tissue border whereas the trailing edge is unrelated to the measured dimension, mainly related to

17 ultrasound frequency.(Sarkola et al. 2010; Wendelhag et al. 1991) As a result, IMT needs to

18 be measured leading edge to leading edge from the vascular far wall for the measurements

19 to be accurate.(Wikstrand 2007) The measurement of arterial intima layer thickness (IT),

20 arterial wall layer thicknesses in small peripheral arteries, and arteries in the pediatric

21 population is, thus, limited using conventional HRU frequencies due to insufficient ultrasound resolution.(Foster et al. 1993; Sarkola et al. 2010; Sundholm et al 2015)

Very-high resolution ultrasound (VHRU, 25-55MHz, axial resolution $0.105-0.045 \mathrm{~mm}$ ) provides the opportunity to image vascular structures in more detail in vivo, limited mainly by penetration depth. VHRU is able to assess the IMT of peripheral conduit muscular arteries, and the adventitial thickness (AT), seen as a triple line pattern, with additional echolucent and echogenic zones.(Sarkola et al. 2010) The non-invasive measurement of IT with very- 
1 high resolution ultrasound frequencies, similar to the use of intravascular ultrasound,(Siegel

2 et al. 1993) has previously been validated using a leading-to-trailing edge method applied to

3 the first echogenic zone of the far wall blood-intima interface.(Choi et al. 2009; Dangardt et

4 al. 2018; Osika et al. 2007; Rodriguez-Macias et al. 2001) However, the leading-to-trailing

5 edge method of IT has lately been questioned in validation studies using healthy arterial

6 specimens. It has been shown that VHRU is unable to quantify intimal thickness in subjects

7 with an intimal thickness below ultrasound axial resolution (as reviewed in Sarkola et al.

82010 discussion). In a more recent study a distinct four-line pattern with an additional

9 echolucent zone separating the first echogenic zone of the blood-intima interface into three

10 separate zones has been described in relation to radiotherapy among long-term childhood

11 cancer survivors.(Vatanen et al. 2015) The study interpreted the finding, a four-line pattern,

12 as a thickened intima and a sign of early vascular aging but without histological verification

13 of the measurement.

The aim of this study was to validate VHRU derived IT measurements in comparison to histology, and to explore the distinct four-line pattern observed in the VHRU image. Our hypothesis was that the additional region in the distinct four-line pattern corresponds to the

17 IT in arteries with intimal thickening. We further explored the presence of the four-line pattern

18 in relation to age and cardiovascular risk factors.

\section{Material and Methods}

We prospectively recruited 74 consecutive patients with suspected giant cell arteritis

21 (GCA) referred to the unit of Vascular Surgery for temporal artery biopsy as part of routine diagnostics between 8/2015 and 2/2018. Exclusion criteria were any sign of inflammation on histology, missing histology or diagonally sliced histology precluding histological measurements, and subjects without $55 \mathrm{MHz}$ VHRU image. Subject characteristics were recorded at presentation using a standard questionnaire filled-in by the investigator and by reviewing patient records to assess background information on cardiovascular risk including smoking history, lipid disorders, diabetes, and hypertension, and current medications. The 
1 local ethics board and the hospital approved the research protocol, and written consent was

2 obtained from the participants.

3 Ultrasound systems

$4 \quad$ Two different ultrasound systems were used in this study, the Vevo 770

5 (VisualSonics, Toronto, ON, Canada) for the first 41 patients and, due to malfunction of the

6 Vevo 770, Vevo MD (VisualSonics, Toronto, ON, Canada) for the following 33 patients. The

7 Vevo 770 was equipped with mechanical RMV-710B, RMV-712, RMV-708 transducers with

8 center frequencies 25,35 and $55 \mathrm{MHz}$ respectively. The Vevo MD was equipped with

9 electronic UHF22, UHF48 and UHF70 transducers, with 15, 30 and 50MHz center

10 frequencies respectively. Further comparison of the ultrasound systems is available in

11 Supplemental table 1.

12 VHRU IT validation

13 Vascular ultrasound images were obtained 1h prior to biopsy by one skilled

14 investigator (JS) using a $55 \mathrm{MHz}$ transducer (axial resolution $15.4 \mu \mathrm{m} /$ pixel) with the Vevo

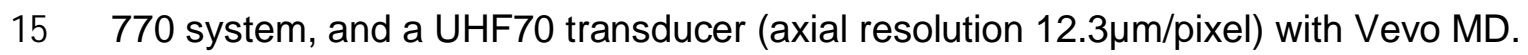

16 Superficial temporal arteries were screened bilaterally for pathology proximal to the vessel

17 bifurcation using VHRU. Scanning area was marked on the skin at the end of imaging to

18 guide the surgeon and to ensure the biopsy was matched to the site of imaging. IT and IMT

19 was measured by one skilled investigator (JS) from the images offline with manufacturer

20 supplied vendor software Vevo 3.0.0 (Vevo 770) and VevoLab 2.0.0 (Vevo MD) in end-

21 diastole using both far wall leading-to-leading edge and leading-trailing edge methods with

22 electronic calipers prior to histological processing. Measurements were done at the central

23 section of the VHRU images as the biopsy would be sectioned from the middle of the

24 specimen. The mean of three measurements was used in analyses. Measurements for a

25 subset $(n=31)$ of images were independently repeated after 1 -month by the first investigator

26 to assess intra-observer agreement. Inter-observer agreement was assessed by 
1 independent measurements performed on the same subset by a second skilled investigator

2 (TS). Image quality was subjectively evaluated in all images and grouped into three quality

3 classes: 3 . Highest quality, with the far wall visible across the entire images, 2. moderate

4 quality, the far wall visible across most of the images, 1. low quality, with the far wall visible

5 in only a small part of the image.

6 Biopsy and histology

$7 \quad$ The biopsy procedure was performed as routine GCA diagnostics at the Helsinki

8 University Central Hospital Department of Vascular Surgery. The biopsy specimens were

9 fixed in formalin and cut in transverse sections, stained with hematoxylin and eosin (H\&E)

10 stain and Verhoff's elastic stain (VEG).(Alturkistani et al. 2015) Biopsies were evaluated for

11 vascular pathology at a certified pathology unit (HUSLAB). Only negative biopsies without

12 any signs of vascular inflammation were included in this study.(Cavazza et al. 2014) Twenty

13 specimens were positive for GCA, three biopsies did not include arterial structures and eight

14 of the histological specimens were sectioned diagonally precluding comparable histological

15 measurements with VHRU arterial layer thickness. VHRU images of sufficient resolution

16 were missing in six subjects. Remaining 37 subjects were included in the study. Biopsy

17 specimens were sectioned in transverse section. Histological sections were evaluated using

18 optic microscopy, photographed at 10x zoom (Nikon Eclipse 80i \& Digital Sight DS-5M,

19 Tokyo, Japan) and IT and IMT later measured offline using Image 1.51J8 (National

20 Institutes of Health, Bethesda, MD, USA)(Schneider et al. 2012) with electronic calipers, as a

21 mean of 10 different measurements, covering the whole circular vascular wall to avoid error

22 due to local differences in vascular wall dimensions.

\section{VHRU imaging of peripheral conduit arteries}

The presence of four-line pattern was also assessed in peripheral conduit arteries in

25 a majority of the GCA cohort with VHRU. Peripheral conduit artery imaging was not

26 performed in some subjects due to time constraint at the research appointment. Images 
1 were obtained from bilateral common carotid arteries, the right radial, and right brachial

2 artery. Carotid images ( $n=30)$ were obtained, according to guidelines(Stein et al. 2008), $1 \mathrm{~cm}$

3 proximal to the carotid bulb using the $25 \mathrm{MHz}$ (Vevo 770) or UHF22 (Vevo MD) transducers.

4 Common carotid artery images were evaluated for plaque presence throughout the carotid

5 bulb and the proximal parts of the external carotid artery. Plaques were defined according to

6 the Mannheim consensus as focal thickening of IMT fulfilling one of the following criteria: 1 .

7 IMT $>1.5 \mathrm{~mm}$, or 2. IMT increase of $0.5 \mathrm{~mm}>50 \%$ compared to the surrounding IMT. (Touboul

8 et al. 2012) Plaque burden was further graded according to plaque number as single or

9 multiple plaques. Radial artery images $(n=34)$ were acquired $1 \mathrm{~cm}$ proximal to the palma

10 manus using the $55 \mathrm{MHz}$ (Vevo 770) or UHF70 (Vevo MD) transducers, and brachial arteries

$11(\mathrm{n}=28)$ were imaged $3 \mathrm{~cm}$ proximal to the cubital skin fold using $35 \mathrm{MHz}$ (Vevo 770) or

12 UHF48 (Vevo MD) transducers. IMT and intima-media-adventitia thickness (IMAT) were

13 measured from the far wall using the leading-edge method in end-diastole.(Sarkola et al.

$142010)$

15 Radial artery four-line pattern in relation to age

16 To broaden the age spectrum and investigate presence of four-line pattern over age,

17 we combined our GCA sample (age 40-86, n=64) with a convenience sample of subjects

18 recruited as part of other projects (final sample $n=444$ ). The convenience sample consisted

19 of 1 . healthy children and adolescents (age 0-18 yrs, $n=139$, previously published study

20 (Sarkola et al. 2012)), 2. teenagers with type 1 diabetes (age 13-16 yrs, $n=39$, unpublished),

21 3. healthy males (age 20-46 yrs, $n=24$, unpublished), and 4 . women with obesity and or

22 gestational diabetes (age $28-51 \mathrm{yrs}, \mathrm{n}=178$, unpublished). The convenience sample is

23 further described in supplemental table 2. To assess IMT and the presence of the four-line

24 pattern (IT) in relation to age, VHRU images of the radial artery were obtained with $55 \mathrm{MHz}$

25 (or UHF70) and assessed as mentioned above.

26 Data analysis 
Results are reported as mean with SD, median with minimum and maximum values,

2 and ratios, as appropriate. Student's T-test was used for comparison between groups.

3 Comparisons between independently obtained ultrasound and histology measurements as

4 well as intra- and inter-observer agreements were quantified by calculating the mean

5 difference, $95 \%$ limits of agreement, coefficient of variation (CV) and intraclass correlation

6 coefficient (ICC). Ultrasound and histology measurements were further compared using

7 Bland-Altman plots.(Bland and Altman 1986) The diagnostic utility of intimal thickening using

8 the presence of four-line pattern was evaluated using receiver operating characteristics

9 (ROC) analysis. Multiple linear regression was used to assess the effects of age and

10 cardiovascular risk factors on histological IT. The occurrence of four-line pattern in relation to

11 age and radial artery intima-media thickness was assessed using logistic regression.

12 Statistical analysis was done using SPSS version 24 (IBM, Armonk, NY, USA) and STATA

13 MP 15.1 (StataCorp LCC, College Station, TX, USA).

15 Results

37 patients were included in the validation study (Vevo $770 \mathrm{n}=20$, and Vevo MD

$17 \mathrm{n}=17)$. Patient mean age was 67 (SD 9,8) years, there were $24(65 \%)$ females, $4(11 \%)$

18 subjects reported current daily and 16 (43\%) previous daily smoking, 17 (46\%) were treated

19 for hypertension, 9 (24\%) for type 2 diabetes, 13 (35\%) for hypercholesterolemia, and 4

$20(11 \%)$ had a history of coronary artery disease in angiography.

21 Validation of VHRU IT and the four-line pattern

In temporal artery VHRU images intimal thickening was observed as a separation of

23 the traditional first echogenic zone into three separate zones (1-3). Compared to histology,

24 the four-line pattern of the far wall in VHRU images consisted of the blood-intima interface

25 (zone 1), echolucent intima core (zone 2), echodense IEL (internal elastic lamina), i.e.

26 intima-media interface (zone 3), echolucent media layer (zone 4), echodense EEL (external 
1 elastic lamina), i.e. media-adventitia interface (zone 5), echolucent adventitia (zone 6) and

2 echodense adventitia-extravascular fat interface (zone 7) (Figure 1a and b) . In the setting of

3 a thin intima the first 3 echo zones (zones 1-3 in figure 1c) were fused. The adventitial

4 thickness of the temporal artery was bordering the resolution of the VHRU method (mean

5 thickness $0.06 \mathrm{~mm}+/-0.02 \mathrm{~mm}$ ) leading to a fusion of the echo zones $5-7$ in most images, as

6 seen in figure 1c. The far wall four-line pattern in VHRU images of the temporal artery

7 (Figure 1b) was similar to the far wall VHRU images of an aged muscular radial artery

8 (Figure 2c), consistent with a thickened intima layer in the radial artery.

9 The mean histological temporal artery IT in the sample was 0.10mm (SD: 0.05;

10 range: $0.02-0.22 \mathrm{~mm}$, Supplemental figure 1$)$. Temporal artery four-line pattern, i.e.

11 measurable IT, was identifiable in 28 patients (76\%) using VHRU. The mean histological IT

12 in images with no four-line pattern on VHRU was $0.04 \mathrm{~mm}$ (SD: 0.04; range 0.02-0.12mm),

13 with $8 / 9$ arteries having an intimal thickness less than $0.06 \mathrm{~mm}$. ROC-analysis of four-line

14 presence and IT on histology gave an AUC of $0.99(95 \% \mathrm{Cl}: 0.97-1.00)$ with the 4-line pattern

15 predicting a histological IT $>0.06 \mathrm{~mm}$ with a sensitivity of $96.3 \%(95 \% \mathrm{Cl}: 81.0-99.9 \%)$ and a

16 specificity of $100.0 \%(95 \% \mathrm{Cl}: 66.3-100.0 \%)$. All images were of high or moderate quality

17 (quality classes 3 and $2, n=17$ and $n=20$, respectively).

Ultrasound measurements of IT and IMT agreed with histological measurements

19 (Table 1 and Figure 3) confirming method accuracy. Intra- and inter-observer agreement of

20 the IT and IMT measurements were good (Table 2 and Figure 3). We further compared the

21 histological agreements using the different ultrasound devices Vevo 770 and the Vevo MD

22 (Supplemental table 3), both agreeing with histology. The Vevo MD had slightly higher ICC

23 compared to the Vevo 770 (ICC $0.867,95 \% \mathrm{Cl} 0.603-0.955$ and ICC $0.97195 \% \mathrm{Cl} 0.901-$

24 0.992) for IT measurements, a difference mainly related to an outlier in the Vevo 770 sample

25 (ICC $0.93195 \% \mathrm{Cl} 0.785-0.978$ after exclusion of the outlier), with no change in accuracy

26 over time suggesting that the differences were unrelated to a learning curve. Images of 
1 higher quality (quality class 3 ) had slightly higher accuracy than those with moderate quality

2 (quality class 2 ) with $C V \% 12.8$ and $23.6 \mathrm{p}=0.098$, respectively.

The leading-to-trailing edge VHRU measurements of blood-intima interface (fused

4 zone 1-3) in arteries with thin $(<0.06 \mathrm{~mm})$ IT consistently overestimated histological IT (mean

5 difference $0.018 \mathrm{~mm} 95 \% \mathrm{CI}$ LOA $-0.004-0.032 \mathrm{~mm}$ ) with bias related to the histological IT

6 level (Supplemental figure 2a). Furthermore, leading-to-trailing edge VHRU measurements

7 of IT (zones 1-3) in arteries with visible intimal thickening systematically overestimated IT

8 (mean difference 0.051, 95\%LOA 0.019-0.084), with constant bias in the measurement over

9 the range of histological IT (Supplemental figure 2b). The bias in the leading-to-trailing edge

10 VHRU measurement is further clarified in Supplemental figure 3.

11 In a linear regression model temporal artery histological IT $[\mu \mathrm{m}]$ was significantly

12 predicted by age [years] $(\beta=1.7 p=0.038)$, hypertension [y/n] $(\beta=42.2 p=0.020)$, diabetes [y/n]

$13(\beta=34.2 p=0.044)$, but not by smoking [10 pack years] $(\beta=6.8 p=0.069)$, or

14 hypercholesterolemia $[y / n](\beta=-26.7 p=0.141)$. The adjusted $R^{2}$ of the model was 0.404 ,

$15 \mathrm{p}<0.001$ (supplemental table 4).

16 In vivo peripheral arterial layer thickness and presence of plaques in GCA group.

Carotid screening was feasible using the $25 \mathrm{MHz}$ in all 30 subjects, whereas the

$35 \mathrm{MHz}$ transducer had insufficient penetrance to clearly view the far wall of the carotid

artery. $40 \%$ of the subjects had identifiable plaques in the carotid arteries, with a majority

20 having multiple plaques. None of the carotid arteries showed separation of the first

21 echogenic zone. The $55 \mathrm{MHz}$ transducer had sufficient penetrance to image the radial artery

22 in all subject and there was an identifiable four-line pattern in $68 \%$ of the subjects. The deeper situated brachial artery required the $35 \mathrm{MHz}$ transducer (and $25 \mathrm{MHz}$ in 3 subjects) to

24 view the vascular far wall. The four-line pattern was identifiable in only one (4\%) brachial

25 artery (supplemental table 5.) 
In a convenience sample of radial artery VHRU images IMT increased with age and

2 the four-line pattern was identified in 51/444 (11.7\%) subjects aged $>36 y$ rs (supplemental

3 figure 4.), but not in younger subjects. The presence of the four-line pattern was

4 independently predicted by both age ([10yrs] OR 3.077; CI95\% 2.125-4.456; $p<0.001)$ and

5 IMT ([0.1mm] OR 4.629; CI95\% 1.631-13.140; $p=0.004)$ in a logistic regression model

6 (supplemental table 6). The feasibility of radial artery VHRU was excellent and adequate

7 imaging was obtained in all patients attempted.

\section{Discussion}

The aim of this study was to validate the vascular non-invasive VHRU method with

10 histology to assess whether the leading-to-leading-edge measurement of the first echolucent

11 region in the four-line pattern corresponds to the IT of the artery. The data shows that the

12 VHRU method provides an accurate and reliable measurement of IT in superficial arteries

13 with layer thickness exceeding axial ultrasound resolution, and that the presence of a four-

14 line pattern is consistent with IT $>0.06 \mathrm{~mm}$. This method provides the opportunity to investigate the vascular health in the aging population noninvasively in vivo.

We further show that intimal thickness increases with age and cardiovascular risk

17 factors, and that the four-line pattern is present in peripheral muscular arteries in a substantial proportion (76\%) of aging subjects, even more prevalent than carotid plaques.

Whereas there was a visible four-line pattern in a majority of the temporal and radial arteries in the GCA cohort, it was absent in all but one brachial artery. This might be due to the lower frequency used or differences in the vascular aging process between the arteries.

There have been previous attempts to validate the IT measurement using noninvasive VHRU. Rodriguez-Macias et al (2001) reported systematic overestimation of

24 ultrasound derived IT using $25 \mathrm{MHz}$. Moreover, Osika et al (2007) compared ultrasound 25 images of the human mesenteric artery obtained with $55 \mathrm{MHz}$ with histology (IT ranging from $26 \quad 100-400 \mu \mathrm{m})$ and showed a good correlation between measurements. The studies 
1 implemented the method on in vivo images measuring the thickness of the echogenic zone

2 of the blood-intima interface with the leading-to-trailing edge method in muscular and carotid

3 arteries suggesting that it represents the intimal layer.(Osika et al. 2007; Rodriguez-Macias

4 et al. 2001) Sarkola et al (2010) found no correlation between the thickness of the echogenic

5 blood-intima interface and histological intima thickness in histology in healthy arterial

6 specimens with thin IT obtained from rabbits and pigs and further reported that the

7 measured interface thickness increased with decreasing ultrasound frequency, and

8 concluded that histological IT was beyond VHRU resolution in healthy arteries.

9 The IT of healthy arteries, consisting of a layer of endothelial cells and the internal

10 elastic lamina, typically measures $10-30 \mu \mathrm{m}$ as shown by histological data.(Kölliker 1854;

11 Velican and Velican 1981) The healthy intima is beyond ultrasound axial resolution even for

12 VHRU. The theoretical minimum measurable thickness of a vascular layer using the leading-

13 edge method is three pixels, i.e. $3^{\star} 0.0123=0.0369 \mathrm{~mm}$ for the UHF70 transducer and slightly

14 higher for the $55 \mathrm{MHz}$ transducer. Non-invasive imaging at this level requires optimal

15 conditions, and in our experience, the layer thickness quantifiable with an acceptable level of

16 certainty is somewhat higher ( $5 \mathrm{px}$, i.e. $0.06 \mathrm{~mm})$. The measurement of arterial IT is

17 dependent on ultrasound frequency, vessel size and location due to reduced penetrance of

18 the higher frequencies used. We did not find any consistent difference in accuracy between

19 the two ultrasound systems, with no considerable difference in axial resolution. Further, age

20 related changes in the vascular wall including fragmentation of the IEL and increasing

21 heterogeneity of the wall structure is inevitably related to reduced image quality, seen as a

22 trend for reduced accuracy not reaching significance in our sample.

23 Our results confirm previous validations for ultrasound derived IMT and shows that

24 the far wall four-line pattern of the VHRU image indicates an intimal layer with a quantifiable

25 thickness. Furthermore, we show that the leading-to-leading edge method provides a more

26 accurate measure of intimal thickness than the leading-to-trailing edge method applied in

27 previous IT validations. These findings using human arterial specimens confirm a systematic 
1 overestimation of IT using the leading-to-trailing edge method to assess the blood-intima

2 interphase in healthy vessels, with a very thin intima on histology, as previously

3 shown.(Sarkola et al. 2010) Our findings demonstrate that in arteries with thin IT, beyond the

4 axial resolution of the method, the IT consistently correspond to approximately three pixels,

5 and thus giving a bias equal to three pixels minus histological IT (mean difference 0.018

$6 \mathrm{~mm}$ ), whereas in arteries, with a visible separation of the intima from the intima-media

7 complex, incorporation of the trailing edge includes part of the media, again, consistent with

8 three pixels (mean difference $0.051 \mathrm{~mm}$, supplemental figure 2). The present results support

9 recommendations that leading-to-leading edge measurements should be used to quantify

10 intimal thickening displayed as a four-line pattern in the VHRU image similar to the far wall

11 arterial IMT measurement.(Wendelhag et al. 1991)

12 The main limitation of this study is that arterial specimens from temporal arteries

13 were included only. However, histologically the temporal artery is a muscular artery with a

14 morphology resembling that of other peripheral conduit arteries that may be imaged with

15 VHRU frequencies. The results should therefore be applicable for the assessment of arterial

16 IT. Another limitation is that the subjects were recruited from patients remitted for TA biopsy

17 due to suspected GCA. We did exclude patients with any sign of vascular inflammation, and

18 vascular changes should mainly be related to cardiovascular risk factors. The prevalence of

19 cardiovascular risk factors in our subjects was similar to the average elderly population,

20 suggesting applicability of this method in this age group.(Jain and Paranjape 2013; Lionakis

21 et al. 2012) A further limitation is that we used two different ultrasound systems without cross

22 validation. The transducers used are almost similar in regards of resolution and penetrance,

23 and both agreed well with histology. The strength of our study is the histological comparison

24 to anatomically matched in vivo imaging of a relatively large sample of arterial specimens

25 with a range of intimal thickening.

26 Conclusion 
We present a novel non-invasive very-high resolution ultrasound-based method for

2 the quantification of thick IT of superficial arteries in the aging population. The measurement

3 is based on identification of a four-line pattern of the arterial far wall appearing in arteries

4 with a thickened intima layer $(>0.06 \mathrm{~mm})$. Our results support the use of the leading-to-

5 leading edge method of the arterial far wall in layer thickness quantification. The leading-to-

6 trailing edge method systematically overestimated histological layer thickness. This

7 technique will provide the opportunity to explore early subclinical atherosclerotic changes in

8 the arterial wall increasing with age.

9 Sources of funding

10 This study has been supported by grants from the Sigrid Juselius Foundation, The

11 Medical Society of Finland, and Finnish Foundation for Pediatric Research, Perklen

12 foundation, Medicinska understödsföreningen Liv och Hälsa, and the Stockmann

13 Foundation.

14 Conflict of interest

15 The authors declare that there is no conflict of interest. 
1 References

2 Alturkistani HA, Tashkandi FM, Mohammedsaleh ZM. Histological Stains: A Literature

3 Review and Case Study. Glob J Health Sci 2015;8:72-9.

4 Bland JM, Altman DG. Statistical methods for assessing agreement between two methods of 5 clinical measurement. Lancet 1986;1:307-10.

6 Burke GL, Evans GW, Riley WA, Sharrett AR, Howard G, Barnes RW, Rosamond W, Crow

7 RS, Rautaharju PM, Heiss G. Arterial wall thickness is associated with prevalent

8 cardiovascular disease in middle-aged adults. The Atherosclerosis Risk in Communities

9 (ARIC) Study. Stroke 1995;26:386-91.

10 Cavazza A, Muratore F, Boiardi L, Restuccia G, Pipitone N, Pazzola G, Tagliavini E, Ragazzi

11 M, Rossi G, Salvarani C. Inflamed temporal artery: histologic findings in 354 biopsies, with

12 clinical correlations. Am J Surg Pathol 2014;38:1360-70.

13 Choi Y, Youn H, Youn J, Park C, Oh Y, Chung W. Measurement of the Intimal Thickness of

14 the Carotid Artery: Comparison Between $40 \mathrm{MHz}$ Ultrasound and Histology in Rats.

15 Ultrasound Med Biol 2009;35:962-6.

16 Chowdhury UK, Airan B, Mishra PK, Kothari SS, Subramaniam GK, Ray R, Singh R,

17 Venugopal P. Histopathology and morphometry of radial artery conduits: basic study and

18 clinical application. Ann Thorac Surg 2004;78:1614-21.

19 Dangardt F, Charakida M, Chiesa S, Bhowruth D, Rapala A, Thurn D, Schaefer F, Deanfield

$20 \mathrm{~J}$, Shroff R. Intimal and medial arterial changes defined by ultra-high-frequency ultrasound:

21 Response to changing risk factors in children with chronic kidney disease. PLoS One

$22 \quad 2018 ; 13: \mathrm{e} 0198547$. 
1 Enos WF, Holmes RH, Beyer J. Coronary disease among United States soldiers killed in

2 action in Korea; preliminary report. J Am Med Assoc 1953;152:1090-3.

3 Foster FS, Lockwood GR, Ryan LK, Harasiewicz KA, Berube L, Rauth AM. Principles and

4 applications of ultrasound backscatter microscopy. IEEE Trans Ultrason Ferroelectr Freq

5 Control 1993;40:608-17.

6 Jain A, Paranjape S. Prevalence of type 2 diabetes mellitus in elderly in a primary care

7 facility: An ideal facility. Indian J Endocrinol Metab 2013;17:S318-22.

8 Kölliker A. Of The Blood Vessels: Arteries. In: Busk G, Huxley T, eds. Manual of Human

9 Histology. 2nd edition. London: The Sydenham Society, 1854:294,295-301.

10 Lionakis N, Mendrinos D, Sanidas E, Favatas G, Georgopoulou M. Hypertension in the

11 elderly. World J Cardiol 2012;4:135-47.

12 Lorenz MW, Gao L, Ziegelbauer K, Norata GD, Empana JP, Schmidtmann I, Lin HJ,

13 McLachlan S, Bokemark L, Ronkainen K, Amato M, Schminke U, Srinivasan SR, Lind L,

14 Okazaki S, Stehouwer CDA, Willeit P, Polak JF, Steinmetz H, Sander D, Poppert H,

15 Desvarieux M, Ikram MA, Johnsen SH, Staub D, Sirtori CR, Iglseder B, Beloqui O, Engstrom

16 G, Friera A, Rozza F, Xie W, Parraga G, Grigore L, Plichart M, Blankenberg S, Su TC,

17 Schmidt C, Tuomainen TP, Veglia F, Volzke H, Nijpels G, Willeit J, Sacco RL, Franco OH,

18 Uthoff H, Hedblad B, Suarez C, Izzo R, Zhao D, Wannarong T, Catapano A, Ducimetiere P,

19 Espinola-Klein C, Chien KL, Price JF, Bergstrom G, Kauhanen J, Tremoli E, Dorr M,

20 Berenson G, Kitagawa K, Dekker JM, Kiechl S, Sitzer M, Bickel H, Rundek T, Hofman A,

21 Mathiesen EB, Castelnuovo S, Landecho MF, Rosvall M, Gabriel R, de Luca N, Liu J,

22 Baldassarre D, Kavousi M, de Groot E, Bots ML, Yanez DN, Thompson SG, PROG-IMT

23 study group. Predictive value for cardiovascular events of common carotid intima media

24 thickness and its rate of change in individuals at high cardiovascular risk - Results from the

25 PROG-IMT collaboration. PLoS One 2018;13:e0191172. 
1 McNamara JJ, Molot MA, Stremple JF, Cutting RT. Coronary artery disease in combat

2 casualties in Vietnam. JAMA 1971;216:1185-7.

3 Mönckeberg J. Über die Atherosklerose der Kombattanten (nach Obduktionsbefunden).

4 Zentralbl Herz Gefäßkrankheiten 1915:7-10.

5 Nakashima Y, Chen Y, Kinukawa N, Sueishi K. Distributions of diffuse intimal thickening in

6 human arteries: preferential expression in atherosclerosis-prone arteries from an early age.

$7 \quad$ Virchows Archiv 2002;441:279-88.

8 O'Leary DH, Polak JF, Kronmal RA, Manolio TA, Burke GL, Wolfson SK,Jr. Carotid-artery

9 intima and media thickness as a risk factor for myocardial infarction and stroke in older

10 adults. Cardiovascular Health Study Collaborative Research Group. N Engl J Med

$11 \quad 1999 ; 340: 14-22$.

12 Osika W, Dangardt F, Grönros J, Lundstam U, Myredal A, Johansson M, Volkmann R,

13 Gustavsson T, Ming Gan L, Friberg P. Increasing Peripheral Artery Intima Thickness From

14 Childhood to Seniority. Arterioscler Thromb Vasc Bio 2007;27:671-6.

15 Pignoli P. Ultrasound B-mode imaging for arterial wall thickness measurement.

16 Atherosclerosis Reviews 1984:177-84.

17 Pignoli P, Tremoli E, Poli A, Oreste P, Paoletti R. Intimal plus medial thickness of the arterial

18 wall: a direct measurement with ultrasound imaging. Circulation 1986;74:1399-406.

19 Rodriguez-Macias KA, Naessen T, Bergqvist D. Validation of in vivo noninvasive high-

20 frequency ultrasonography of the arterial wall layers. Ultrasound Med Biol 2001;27:751-6.

21 Sarkola T, Manlhiot C, Slorach C, Bradley TJ, Hui W, Mertens L, Redington A, Jaeggi E.

22 Evolution of the arterial structure and function from infancy to adolescence is related to 
1 anthropometric and blood pressure changes. Arterioscler Thromb Vasc Biol 2012;32:2516-

224.

3 Sarkola T, Redington A, Keeley F, Bradley T, Jaeggi E. Transcutaneous very-high-resolution

4 ultrasound to quantify arterial wall layers of muscular and elastic arteries: Validation of a

5 method. Atherosclerosis 2010;212:516-23.

6 Schneider CA, Rasband WS, Eliceiri KW. NIH Image to ImageJ: 25 years of image analysis.

$7 \quad$ Nat Methods 2012;9:671-5.

8 Siegel RJ, Chae JS, Maurer G, Berlin M, Fishbein MC. Histopathologic correlation of the

9 three-layered intravascular ultrasound appearance of normal adult human muscular arteries.

10 Am Heart J 1993;126:872-8.

11 Stein JH, Korcarz CE, Hurst RT, Lonn E, Kendall CB, Mohler ER, Najjar SS, Rembold CM,

12 Post WS, American Society of Echocardiography Carotid Intima-Media Thickness Task

13 Force. Use of carotid ultrasound to identify subclinical vascular disease and evaluate

14 cardiovascular disease risk: a consensus statement from the American Society of

15 Echocardiography Carotid Intima-Media Thickness Task Force. Endorsed by the Society for

16 Vascular Medicine. J Am Soc Echocardiogr 2008;21:93,111; quiz 189-90.

17 Sundholm JKM, Olander RFW, Ojala TH, Andersson S, Sarkola T. Feasibility and precision

18 of transcutaneous very-high resolution ultrasound for quantification of arterial structures in

19 human neonates - Comparison with conventional high resolution vascular ultrasound

20 imaging. Atherosclerosis 2015;239:523-7.

21 Touboul PJ, Hennerici MG, Meairs S, Adams H, Amarenco P, Bornstein N, Csiba L,

22 Desvarieux M, Ebrahim S, Hernandez Hernandez R, Jaff M, Kownator S, Naqvi T, Prati P,

23 Rundek T, Sitzer M, Schminke U, Tardif JC, Taylor A, Vicaut E, Woo KS. Mannheim carotid

24 intima-media thickness and plaque consensus (2004-2006-2011). An update on behalf of 
1 the advisory board of the 3rd, 4th and 5th watching the risk symposia, at the 13th, 15th and

2 20th European Stroke Conferences, Mannheim, Germany, 2004, Brussels, Belgium, 2006,

3 and Hamburg, Germany, 2011. Cerebrovasc Dis 2012;34:290-6.

4 Vatanen A, Sarkola T, Ojala TH, Turanlahti M, Jahnukainen T, Saarinen-Pinkala UM,

5 Jahnukainen K. Radiotherapy-related arterial intima thickening and plaque formation in

6 childhood cancer survivors detected with very-high resolution ultrasound during young

7 adulthood. Pediatric Blood \& Cancer 2015;62:2000-6.

8 Velican D, Velican C. Comparative study on age-related changes and atherosclerotic

9 involvement of the coronary arteries of male and female subjects up to 40 years of age.

10 Atherosclerosis 1981;38:39-50.

11 Wendelhag I, Gustavsson T, Suurkula M, Berglund G, Wikstrand J. Ultrasound

12 measurement of wall thickness in the carotid artery: fundamental principles and description

13 of a computerized analysing system. Clin Physiol 1991;11:565-77.

14 Wikstrand J. Methodological considerations of ultrasound measurement of carotid artery

15 intima-media thickness and lumen diameter. Clin Physiol Funct Imaging 2007;27:341-5.

16 Wilens SL. The Nature of Diffuse Intimal Thickening of Arteries. Am J Pathol 1951;27:825-

1739.

18

19

20 
Table 1.

\section{Histology VHRU}

Mean

$\begin{array}{lllllllll}\text { Histology vs. VHRU } & N & \text { Mean } & \text { SD } & \text { Mean SD } & \text { Difference } & \text { LOA 95Cl\% } & \text { CV\% } & \text { ICC }(95 \% \mathrm{Cl})\end{array}$

$\begin{array}{llllllllll}\text { Intima thickness }[\mathrm{mm}] & 28 & 0.125 & 0.045 & 0.132 & 0.050 & 0.007 & -0.042 ; 0.057 & 19.7 & 0.923(0.833 ; 0.964)\end{array}$

Intima-media

thickness $[\mathrm{mm}] \quad \begin{array}{llllllllll} & 37 & 0.255 & 0.097 & 0.243 & 0.086 & -0.012 & -0.086 ; 0.064 & 15.1 & 0.955(0.912 ; 0.977)\end{array}$

Table 1. Comparison of histology and VHRU measurements. SD -standard deviation; LOA $95 \%$ limits of agreement; CV\% - coefficient of variation (\%); ICC - intraclass correlation; $95 \% \mathrm{Cl}-95 \%$ confidence interval. 
Table 2.

Mean

\begin{tabular}{|cccccccc|}
\hline \multirow{2}{*}{ Intra-observer } & & \multicolumn{7}{c}{ Mean } & & \\
& $\mathrm{N}$ & Mean & $\mathrm{SD}$ & Difference & LOA 95Cl\% & CV\% & ICC (95\% CI) \\
\hline Intima thickness [mm] & 25 & 0.140 & 0.047 & -0.011 & $-0.053 ; 0.032$ & 15.7 & $0.946(0.877 ; 0.976)$ \\
Intima-media thickness [mm] & 31 & 0.246 & 0.090 & -0.006 & $-0.085 ; 0.071$ & 16.1 & $0.951(0.898 ; 0.976)$ \\
\hline Inter-observer & & & & & & & \\
\hline Intima thickness [mm] & 25 & 0.136 & 0.044 & 0.012 & $-0.040 ; 0.065$ & 19.9 & $0.872(0.773 ; 0.943)$ \\
Intima-media thickness [mm] & 31 & 0.240 & 0.085 & 0.025 & $-0.075 ; 0.125$ & 21.2 & $0.857(0.704 ; 0.931)$ \\
\hline
\end{tabular}

Table 2. Intra- and inter-observer comparisons. SD - standard deviation; LOA95\% - 95\% limits of agreement; CV\% - Coefficient of variation (\%); ICC - Intraclass correlation; $95 \% \mathrm{CI}-$ $95 \%$ confidence interval. 
Figures
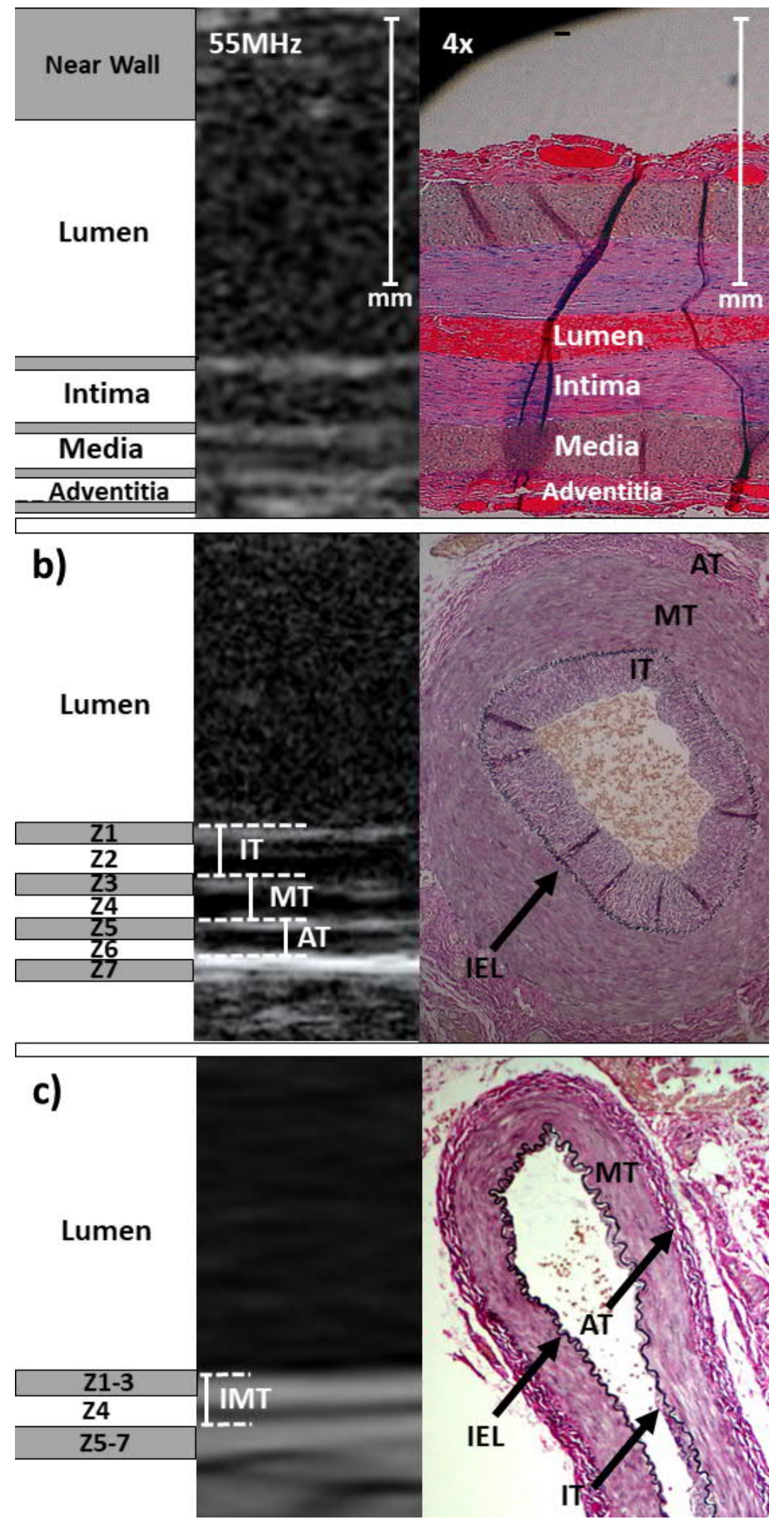

Figure 1. Images of temporal artery histology and corresponding in vivo VHRU (55MHz). a) 4x optic zoom HE-stain histology and VHRU image with identical scales. Note the three layers of the vascular wall is separately distinguishable in the VHRU image. b) Thick 
temporal artery wall (VEG-stain) and VHRU image. Note the far wall is separated in to seven different zones displaying a four-line pattern in the VHRU image. Zone 1: echodense lumen intima interface; Zone 2: echolucent intima core; Zone 3: echodense intima-media interface; Zone 4: echolucent media; Zone 5: echodense media-adventitia interface; Zone 6: echolucent adventitia; Zone 7: echodense adventitia-vascular border. c) Thin intima of temporal artery wall on histology represented by the inner surface of the stained IEL (VEGstain) and on the corresponding VHRU image showing fused echo zones 1-3. echolucent media zone 4. and echodense media vascular wall interface (zones 5-7). Note that the adventitial layer thickness in this temporal artery lacks sufficient thickness to be measured. AT - Adventitia; IT - Intima; MT - Media; IMT - Intima-media thickness; IEL - Internal elastic lamina. 


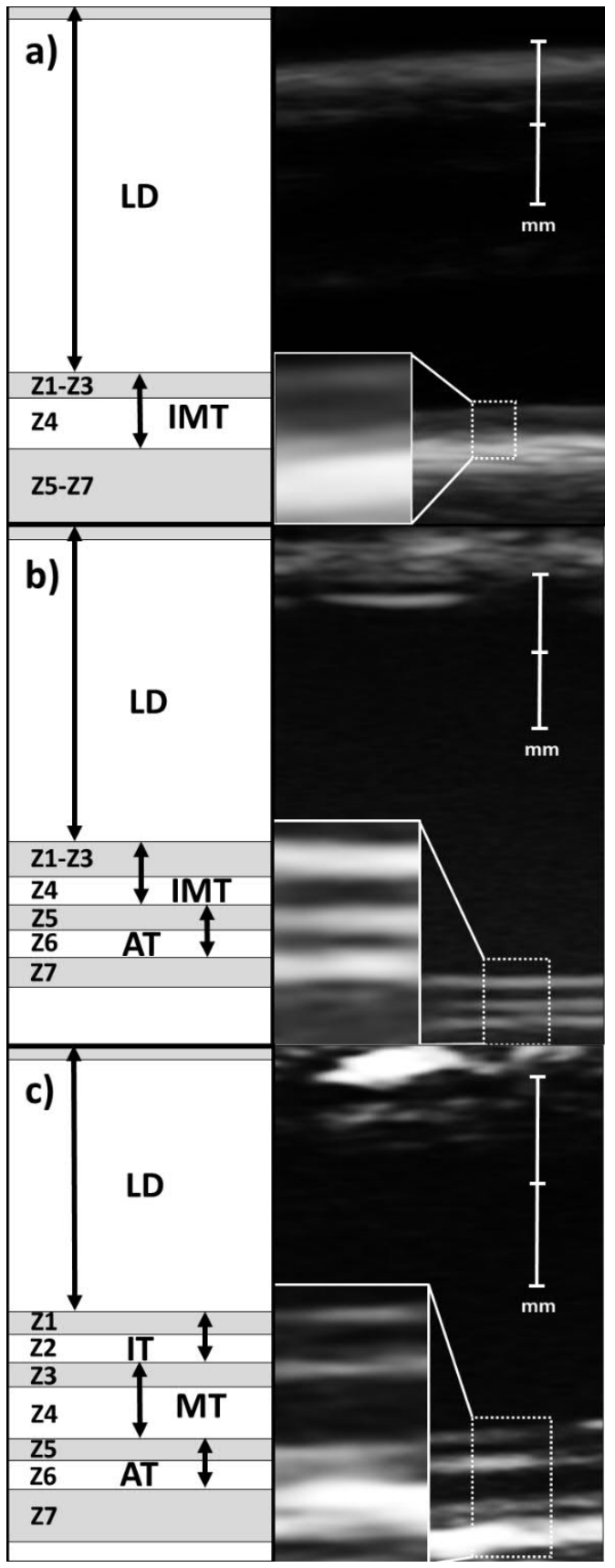

Figure 2. Schematic and VHRU images showing a) the double-line pattern seen in the elastic common carotid artery (52yrs. Female, $25 \mathrm{MHz}$ ) with fused echo zones 1-3 and 5-7 b) triple-line pattern seen in a muscular radial artery (53yrs. Female, $55 \mathrm{MHz}$ ) with separation of the media-adventitial echo zones into three separate echo zones (5-7). and c) the distinct four-line pattern in an aged muscular radial artery (male. $77 \mathrm{yrs}, 55 \mathrm{MHz}$ ). with separation of the intima-media echo zones (1-3) and media-adventitia echo zones (5-7). Please note the interfaces applied in the leading-to-leading edge measurement technique for far wall IT, IMT, and AT. 

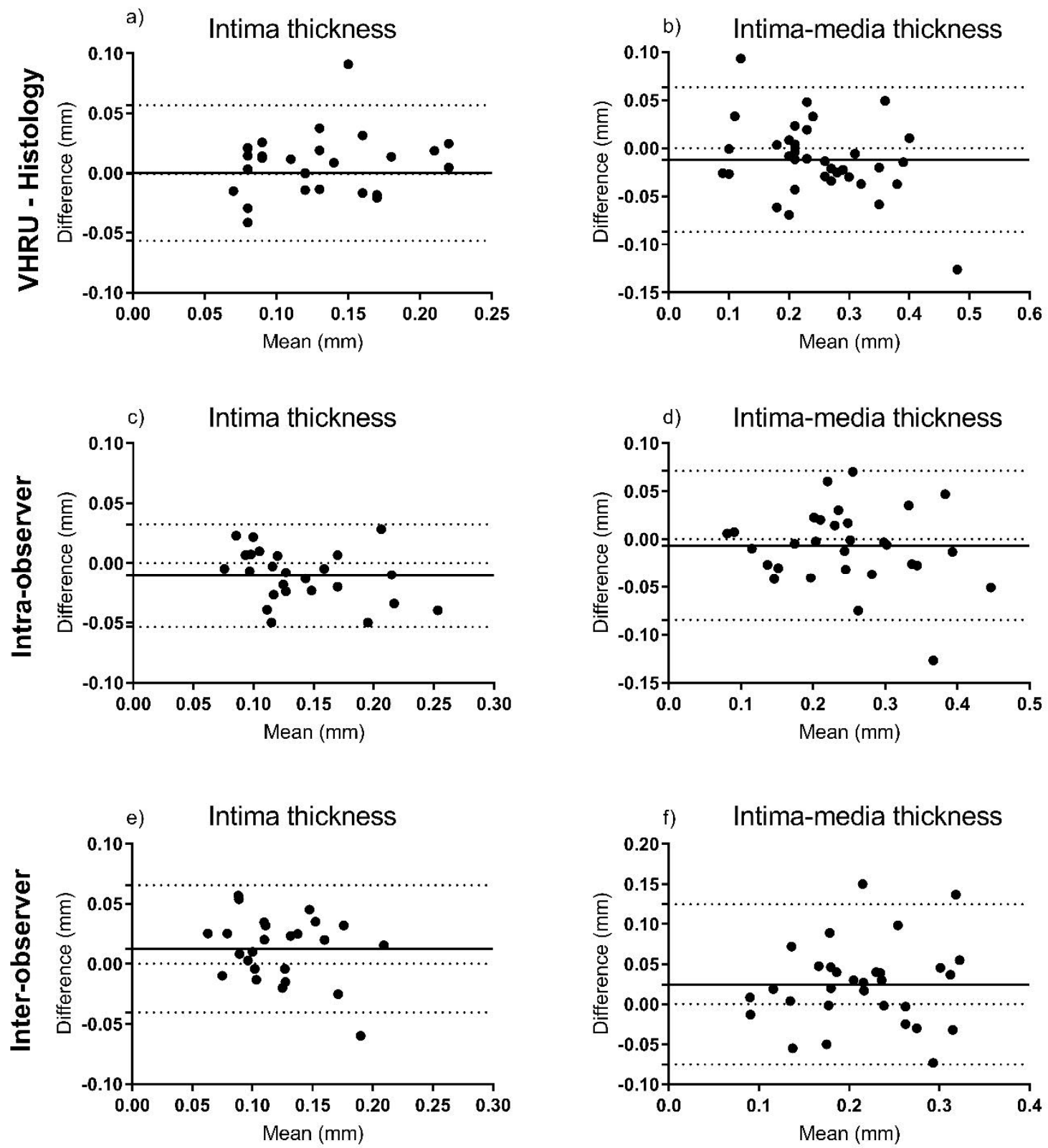

Figure 3. Bland Altman plots of very-high resolution ultrasound (55MHz VHRU) vs. Histology accuracy a) and b). intra-observer agreements c) and d) and inter-observer agreements e) and f) for temporal artery intima (IT) and intima-media thickness (IMT). 
Supplemental Figure Legends

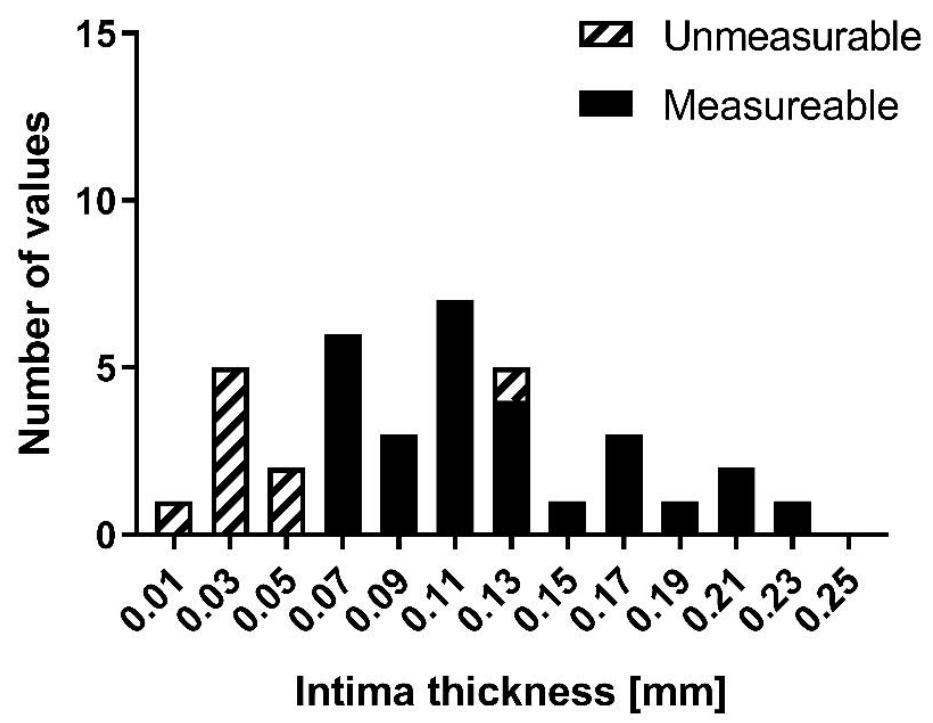

Supplemental figure 1. Distribution of temporal artery intima thickness (IT) on histology separated into groups according to four-line pattern visibility and measurable IT with $55 \mathrm{MHz}$ VHRU. 


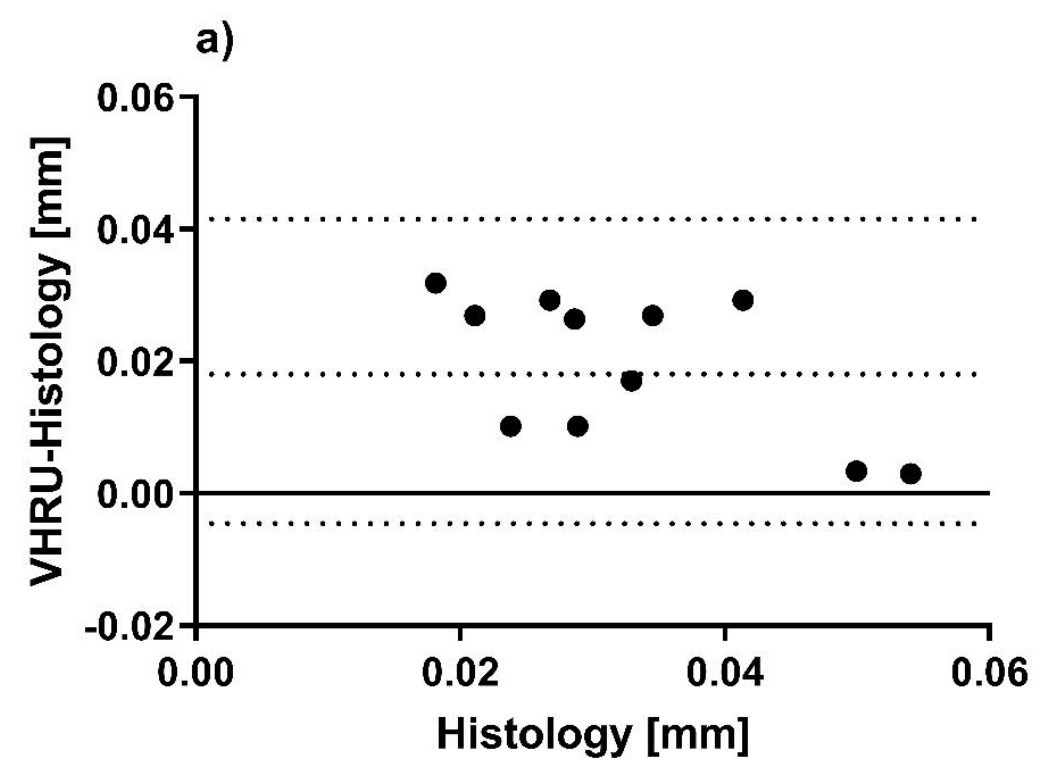

b)

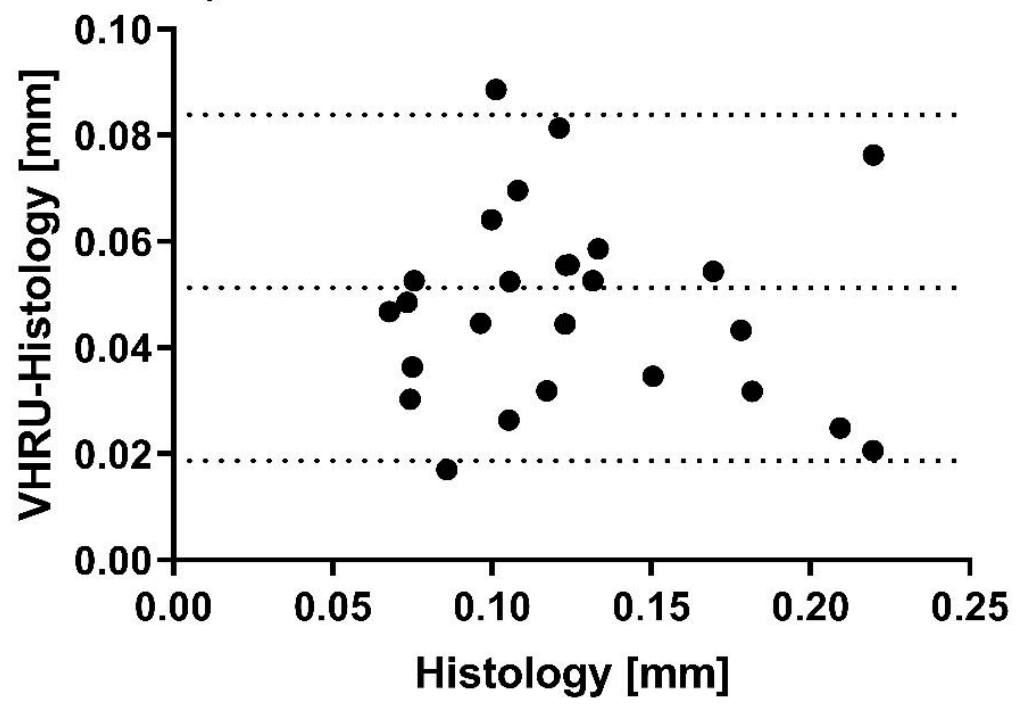

Supplemental figure 2. Bland-Altmant plots comparing very-high resolution ultrasound (VHRU) intima layer thickness (IT) with histology IT using the leading-to-trailing edge measurement technique in the assessment of the VHRU image. a) Leading-to-trailing edge VHRU measurement of blood-intima interface (fused zones 1-3) in arteries with histological IT less than $0.06 \mathrm{~mm}$. b) Leading-to-trailing edge VHRU measurement of the visible IT (zones 1-3 separated in image, measurement from leading-edge of zone 1 to trailing edge of zone 3) in arteries with histological IT $0.06 \mathrm{~mm}$ or more. Note the systematic bias in leadingto-trailing edge VHRU IT measurement in comparison to histological IT in both settings. 


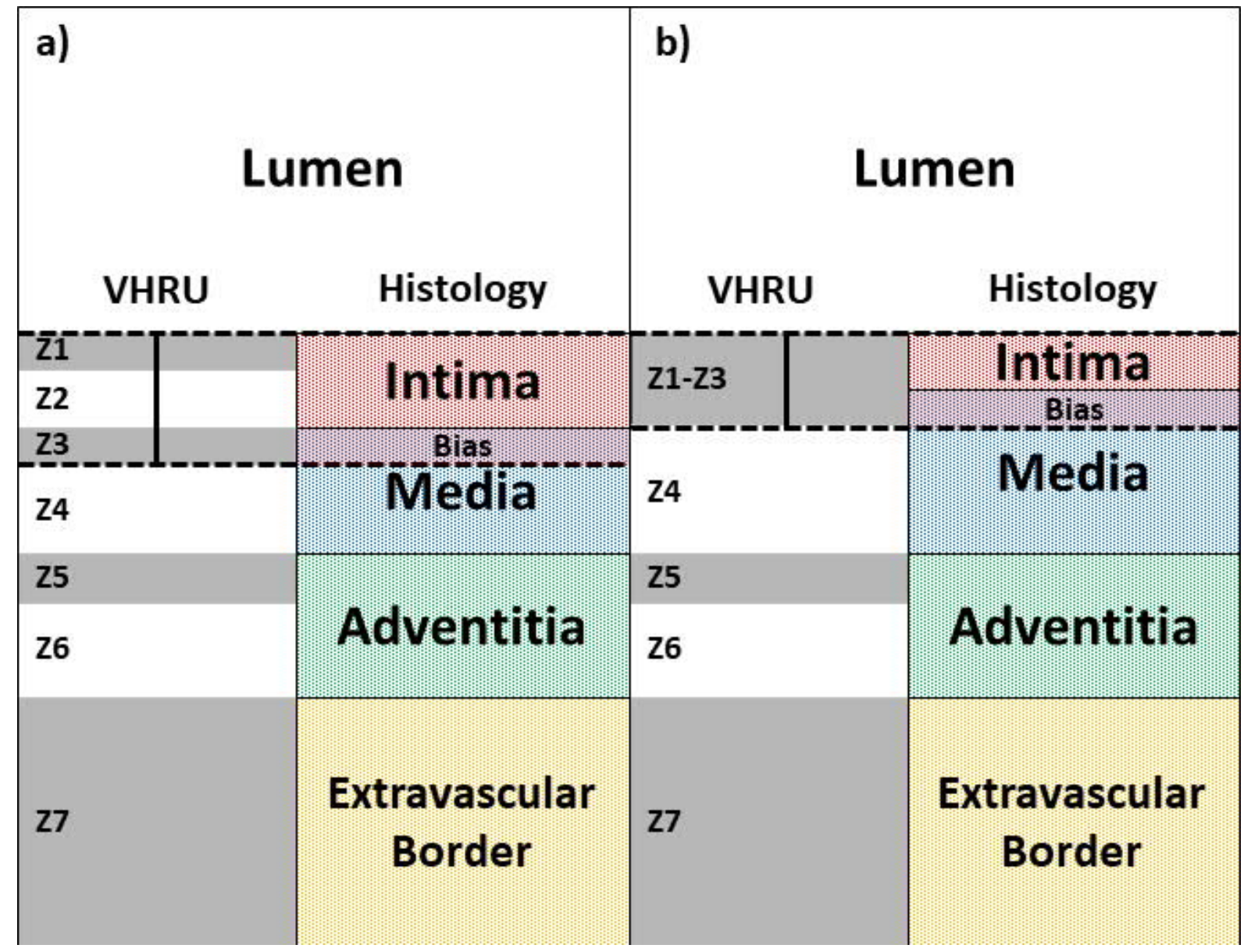

Supplemental figure 3. Schematic image of how measures using the leading-to-trailing edge method induces bias in a) vessels with a thickened intima (separated zones 1-3). and b) vessels with a thin intima (fused zones 1-3). Note how the bias is equal to Z3 in case a). whereas the bias is influenced by the histological intima artery layer thickness (IT) in b) as Z1-Z3 remains constant and non-related with histological IT variance. 


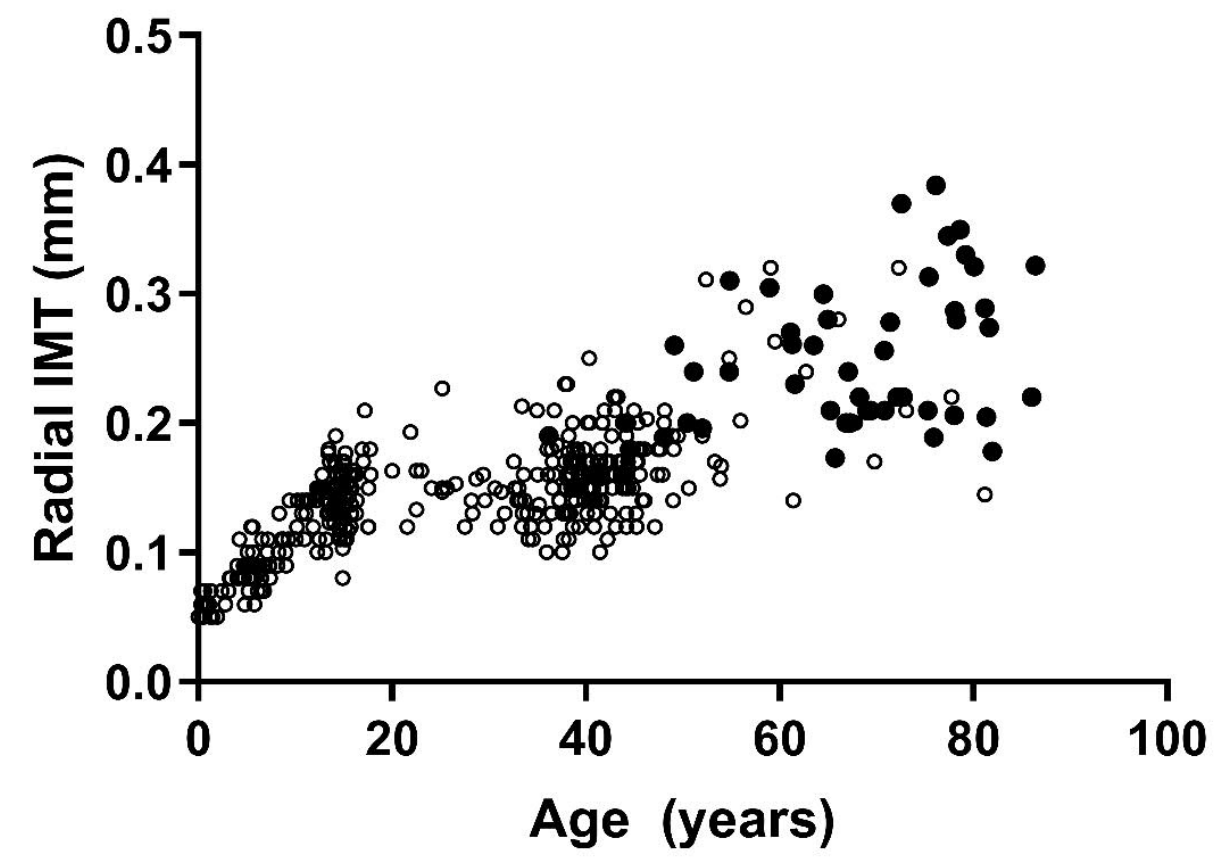

Supplemental figure 4. Radial artery intima-media thickness, from $55 \mathrm{MHz}$ or UHF70 VHRU images, in relation to age including occurrence of visible four-line pattern (black circle) increasing from end of fourth decade of life. 
Supplemental Tables to Sundholm et al Assessing Vascular Intima with Ultrasound 


\begin{tabular}{|c|c|c|}
\hline & Vevo 770 & Vevo MD \\
\hline Release Year & 2005 & 2016 \\
\hline Transducer type & Single Mechanical & Multiple Electrical \\
\hline Image post- & & \\
\hline processing & None & Despeckling filter \\
\hline Multi-focus & No & Yes \\
\hline Transducers & RMV710B & UHF22 \\
\hline Center transmit & $25 \mathrm{MHz}$ & $15 \mathrm{MHz}$ \\
\hline Frequency range & $12-38 \mathrm{MHz}$ & $10-22 \mathrm{MHz}$ \\
\hline Axial Resolution & $35.7 \mu \mathrm{m} / \mathrm{px}$ & $44.8 \mu \mathrm{m} / \mathrm{px}$ \\
\hline Penetrance & $22.5 \mathrm{~mm}$ & $38.4 \mathrm{~mm}$ \\
\hline Transducers & RMV712 & UHF48 \\
\hline Center transmit & $35 \mathrm{MHz}$ & $30 \mathrm{MHz}$ \\
\hline Frequency range & $17-53 \mathrm{MHz}$ & $20-46 \mathrm{MHz}$ \\
\hline Axial Resolution & $19.6 \mu \mathrm{m} / \mathrm{px}$ & $21.8 \mu \mathrm{m} / \mathrm{px}$ \\
\hline Penetrance & $13.0 \mathrm{~mm}$ & $23.5 \mathrm{~mm}$ \\
\hline Transducers & RMV708 & UHF70 \\
\hline Centrer transmit & $55 \mathrm{MHz}$ & $50 \mathrm{MHz}$ \\
\hline Frequency range & $22-83 \mathrm{MHz}$ & $29-71 \mathrm{MHz}$ \\
\hline Axial Resolution & $15.6 \mu \mathrm{m} / \mathrm{px}$ & $12.3 \mu \mathrm{m} / \mathrm{px}$ \\
\hline Penetrance & $8.0 \mathrm{~mm}$ & $10.0 \mathrm{~mm}$ \\
\hline
\end{tabular}

Supplemental table 1. Comparison of the two ultrasound systems and transducers used in this study. 


\begin{tabular}{|lllll|}
\hline Sample & $\mathbf{1 .}$ & $\mathbf{2 .}$ & $\mathbf{3 .}$ & $\mathbf{4}$ \\
\hline $\mathrm{N}$ & 139 & 39 & 24 & 178 \\
Age (Range) & $9.0(0.0-17.8)$ & $14.6(13.2-16.3)$ & $29.8(20.0-46.3)$ & $40.3(27.5-50.6)$ \\
Female (\%) & $58(42 \%)$ & $19(49 \%)$ & $0(0 \%)$ & $178(100 \%)$ \\
BMI Z-score & & & & \\
(Range) & $0.0(-2.1-2.9)$ & $0.57(-1.3-2.4)$ & & $32.2(17.7-45.1)$ \\
BMI (Range) & $18.3(11.7-31.9)$ & $22.5(16.7-34.2)$ & $24.7(20.4-28.6)$ & $10(5.6 \%)$ \\
Diabetes (\%) & $0(0 \%)$ & $39(100 \%)$ & $0(0 \%)$ & $19(10.7 \%)$ \\
Hypertension (\%) & $0(0 \%)$ & $0(0 \%)$ & $0(0 \%)$ & \\
\hline
\end{tabular}

Supplemental table 2. Subject characteristics for the four convenience samples included to assess the presence of the four-line pattern in relation to age. 


\section{Histology VHRU}

Histology vs.

Mean

$\begin{array}{llllllll}\text { VHRU } & N \text { Mean SD } & \text { Mean SD } & \text { Difference } & \text { LOA 95CI\% } & \text { CV\% } & \text { ICC }(95 \% C l)\end{array}$

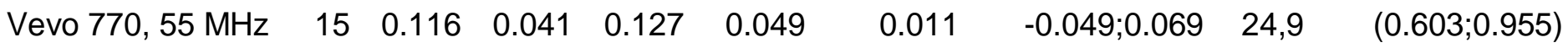

0.971

Vevo MD, $50 \mathrm{MHz} \quad 12 \quad 0.135 \quad 0.050 \quad 0.139 \quad 0.053 \quad 0.004 \quad-0.030 ; 0.037 \quad 12,6 \quad(0.901 ; 0.992)$

Supplemental table 3. Comparison of histology and VHRU measurements using the $55 \mathrm{MHz}$ Vevo 770 and $50 \mathrm{MHz}$ Vevo MD, respectively. SD -standard deviation; LOA - 95\% limits of agreement; CV\% - coefficient of variation (\%); ICC - intraclass correlation; $95 \% \mathrm{Cl}-95 \%$ confidence interval. 


\begin{tabular}{|c|c|c|}
\hline Dependent variable & \begin{tabular}{|l} 
Adjusted \\
R2
\end{tabular} & Model p-value \\
\hline Intima thickness [ $\mu \mathrm{m}]$ & 0.404 & $<0.001$ \\
\hline Independent variables & Beta & p-value \\
\hline Constant & -36.6 & 0.464 \\
\hline Age [years] & 1.7 & 0.038 \\
\hline Hypertension [yes $=1$ no $=0$ ] & 42.2 & 0.02 \\
\hline Diabetes $[$ yes $=1$ no=0] & 34.2 & 0.044 \\
\hline \multicolumn{3}{|l|}{ Hypercholesterolemia [yes $=1$} \\
\hline no $=0]$ & -26.7 & 0.141 \\
\hline Smoking [10 pack years] & 6.8 & 0.069 \\
\hline
\end{tabular}

Supplemental table 4. Linear regression model assessing effects of age and cardiovascular risk factors on histological intima thickness in the GCA sample $(n=37)$. 


\begin{tabular}{|ll|}
\hline Vacular parameters & Mean (SD)/N(\%) \\
\hline Carotid Artery 25MHz [N=30] \\
\hline Intima-media thickness \\
[mm] & $0.65(0.12)$ \\
Plaque presence & $12(40.0 \%)$ \\
Multiple plaques & $9(30.0 \%)$ \\
\hline Radial Artery 55Mhz [N=34] \\
\hline Intima-media thickness \\
[mm] & $0.23(0.06)$ \\
Adventitia thickness [mm] & $0.11(0.03)$ \\
4-line pattern & $23(67.6 \%)$ \\
Intima thickness & $0.11(0.06)^{\mathrm{a}}$ \\
\hline Brachial Artery 35MHz [N=28] & $1(3.5 \%)$ \\
\hline Lumen Diameter [mm] & $3.49(0.59)$ \\
Intima-media thickness & \\
[mm] & $0.30(0.07)$ \\
Adventitia thickness [mm] & $0.17(0.08)$ \\
\hline
\end{tabular}

Supplemental table 5. Vascular dimensions. intimal thickening and plaque findings of carotid. brachial and radial arteries in the GCA sample. ${ }^{a}$ - calculated from arteries with visible fourline pattern. 


\begin{tabular}{|c|c|c|c|}
\hline Dependent variab & & & el p-value \\
\hline Visible 4-line $[0=r$ & $=$ yes $]$ & & $<0.001$ \\
\hline Independent & & & \\
\hline variables & Beta (SE) & OR $(95 \% \mathrm{Cl})$ & $p$-value \\
\hline & -10.326 & & \\
\hline Constant & (1.137) & & \\
\hline Age [10 years] & $1.124(0.189)$ & $3.077(2.125-4.456)$ & $<0.001$ \\
\hline & & 4.629 (1.631- & \\
\hline IMT [0.1mm] & $1.153(0.532)$ & 13.140) & 0.004 \\
\hline
\end{tabular}

Supplemental table 6. Logistic regression model of visible radial artery far wall four-line pattern using VHRU. SE - standard error; OR - odds ratio; $95 \% \mathrm{CI}-95 \%$ confidence interval. 